\title{
A Study on the Actuator Efficiency Behavior of Safety-Related Motor Operated Gate and Globe Valves
}

\author{
Shin Cheul Kang, SungKeun Park, DoHwan Lee, \\ YangSeok Kim and DaeWoong Kim \\ Nuclear Power Laboratory, KEPRI \\ Korea
}

\section{Introduction}

A motor operated valve (MOV) consists of a motor, an actuator, and a valve. Fig. 1 shows a schematic diagram of an MOV. A motor that is bolted to the actuator housing drives the actuator. Attached to the motor shaft is the pinion gear, which drives a gear train. The gear train drives a worm that is splined onto the opposite end of the worm shaft. This worm assembly is capable of moving axially as it revolves with the worm shaft. The axial movement is a means of controlling the output torque of the actuator. The worm drives a worm gear that rotates the drive assembly. As the drive sleeve rotates, the stem nut raises or lowers a valve stem. When the valve is seated or obstructed, then the worm gear can no longer rotate, and the worm slides axially along its splined shaft compressing a spring pack. This axial movement operates a torque switch, causing the motor to be de-energized.

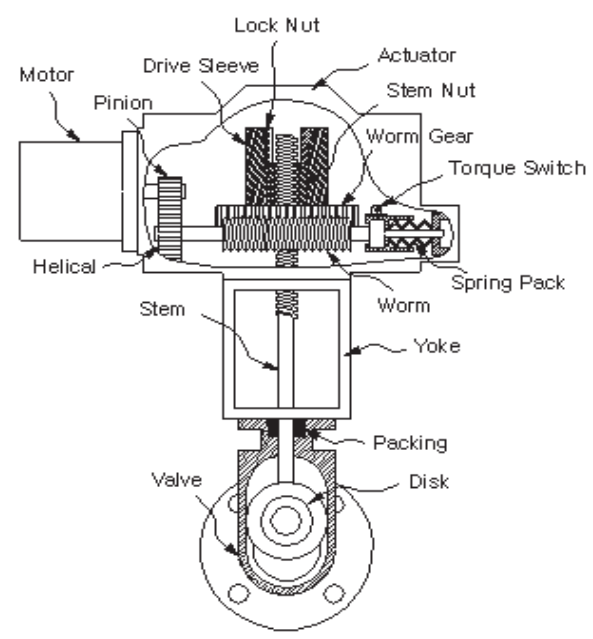

Fig. 1. Schematic diagram of MOV 
An MOV with such operational principles is an essential element to control the piping flow in nuclear power plant or other facilities. In fact, the operational failure of a safety-related MOV in a nuclear power plant can have catastrophic results. Therefore, it is necessary that the operability of the safety-related MOVs should be integral and required in the design basis conditions. The US Nuclear Regulatory Commission (NRC) issued Generic Letter (GL) 89-10 regarding safety-related MOV testing and surveillance (USNRC, 1989). Subsequently, in South Korea, the Korea Institute of Nuclear Safety (KINS) required similar testing and verification, as follows:

- Reviewing and documenting the design basis for the operation of each MOV

- $\quad$ Establishing the correct switch settings

- Demonstrating the MOV to be operable at the design basis differential pressure and/or flow

Once the operability of each MOV was proven, the need arose to preserve the operability of every tested MOV to maintain the safety of nuclear power plants. The USNRC and KINS issued regulatory requirements, which specify periodic verification (PV) of the operability of MOVs. The requirements recommend utilities to develop an effective PV program of MOV design capability, considering the fact that aging can decrease the thrust/torque output of motor actuators (USNRC, 1996). To address the two types of requirements described above, at least in part, Korean nuclear power plants have implemented static diagnostic tests that can provide information on the thrust/torque output of the motor actuator, and any changes to the motor-actuator output as a result of aging effects. The first static test for each MOV had been conducted from 1999 to 2004, in order to guarantee its operability and design basis conditions. The second static test has been conducted from 2005, ongoing to the present, in order to implement PV requirements. Up until 2009, it had been assumed that the actuator efficiency, one of the most important factors in evaluating the motor actuator output, does not degrade over time. In other words, the design efficiency provided by manufacture had been used in the calculation of motor actuator output. In addition, in the event that the design efficiency had not been provided by the manufacturer, the design efficiency of other manufacture with similar motor speed and actuator size had been used.

Therefore, the purpose of this chapter is to confirm the validation of the design efficiency by analyzing the efficiency behavior over time for motor operated gate and globe valves with rising stem, and comparing the design efficiency with the efficiency calculated from a method that is introduced in this chapter.

It is presented herein that most actuators of gate and globe valves have minor variations in efficiency from test-to-test, but no increasing or decreasing trend over time, as well as demonstrating higher efficiency than the design efficiency. The efficiency variations for some actuators with lower motor speed, lower actuator size, and lower gear ratio also were not increased or decreased over time, but their design efficiency was susceptible to decrease below the their original value. For those actuators, the threshold efficiency was calculated for the purpose of replacing their design efficiency.

From 2010, those results with two other evaluation studies over time on stem/stem nut friction coefficient and valve disk/seat friction coefficient have been applied for the PV program of safety-related MOVs in Korean nuclear power plants. The three studies including the contents introduced in this chapter have helped us to develop optimized PV program that can enhance the operability of the valves. Furthermore, they have made key roles in extending the maximum test frequency from 5 years to 10 years. 


\section{Calculation of actuator efficiency}

\subsection{Data acquisition}

As described in Section 1, the diagnostic static tests have been conducted to ensure the motor actuator output of safety-related MOVs for 20 units of nuclear power plants from 1999 to the present in Korea. For each valve, more than two tests have been conducted. The first test was the design basis test from 1999 to 2004, and the second was the periodic test from 2005 to 2009. Each test was composed of one 'as-found' and two 'as-left' tests to compare and analyze conditions before and after maintenance jobs, according to the field test procedures. The comprehensive static test data for each valve were used in this study. In the tests, the actuator torque and the three phases of currents and voltages were measured from the strain gage type sensor attached on the stem, and current and voltage probes installed at the power lines toward the actuator, respectively. Fig. 2 shows the sensors installed to measure currents and voltages at the valve. The measured values for gate and globe valves were used in analyzing their respective actuator efficiency behavior.

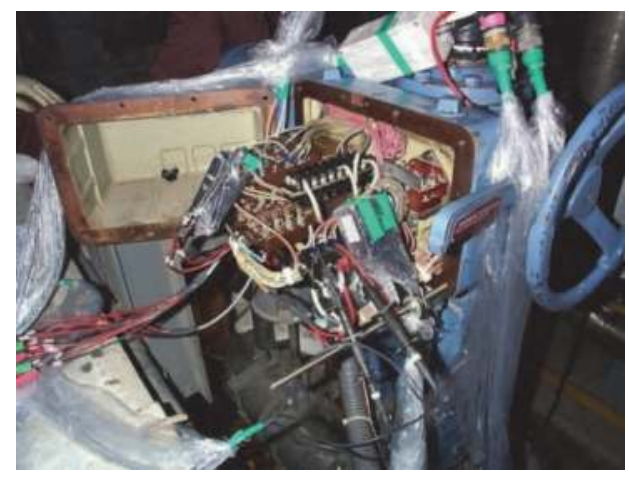

Fig. 2. A picture of installed sensors at a valve test

\subsection{Efficiency calculation process}

The actuator efficiency is a factor transferring motor torque produced by an electric motor into actuator torque, necessary in rotating actuator inner gears. The typical efficiency can be calculated using the following expression:

$$
\eta=\frac{T q}{M T q \times O V R}
$$

Where $\eta$ is the actuator efficiency, $T q[f t-l b]$ is the actuator torque, $M T q[f t-l b]$ is the motor torque, and, OVR is the overall gear ratio provided by the manufacturer. In this study, the equation (1) was used to calculate the efficiency.

\subsubsection{Data preparation}

As shown in equation (1), the values of actuator torque and motor torque can be used to calculate the efficiency. The measured actuator torque in the static tests was applied directly for the equation (1). The motor torque was not measured directly in the static tests. Accordingly, in order to calculate actuator efficiency, a method to estimate motor torque 
was introduced. In this chapter, the motor torque was estimated by a motor torque estimator, NEET (S.C. Kang et al., 2006), which can estimate the motor torque using the three phases of currents and voltages, and resistance values between phases measured in the static tests. The NEET was developed on the basis of several assumptions. First, the stator windings are assumed to be sinusoidally wound to couple only to the fundamentalspace-harmonic component of air-gap flux. Second, the self-inductances of the rotor are assumed not to vary with rotor angular position. Finally, linear magnetics are assumed. Under these assumptions, the air-gap torque produced by a two-phase induction motor, which can be transformed from the three-phase induction motor is given by

$$
T=P\left(\lambda_{s \alpha} i_{s \beta}-\lambda_{s \beta} i_{s \alpha}\right)
$$

Where, $\lambda_{s \alpha}$ and $\lambda_{s \beta}$ are the flux linkages of the two stator phases. $i_{s \alpha}$ and $i_{s \beta}$ are the currents of the two stator phases and $P$ is the number of pole pairs. The currents $i_{s \alpha}$ and $i_{s \beta}$ can be directly measured at the stator terminals. The flux linkages can also be determined from terminal measurements. For a two-phase machine,

$$
\left[\begin{array}{c}
v_{s \alpha} \\
v_{s \beta}
\end{array}\right]=R_{S}\left[\begin{array}{c}
i_{s \alpha} \\
i_{s \beta}
\end{array}\right]+\frac{d}{d t}\left[\begin{array}{c}
\lambda_{s \alpha} \\
\lambda_{s \beta}
\end{array}\right]
$$

Where, $v_{s \alpha}$ and $v_{s \beta}$ are the two stator voltages and $R_{s}$ is the stator phase resistance. Thus, the motor torque is expressed only in terms of stator variables, which can be measured in field test. Except for the NEET, other motor torque estimators can be used in the estimation of motor torque. Fig. 3 shows an example of motor torque signal estimated by NEET using the electrical data acquired from a field test.

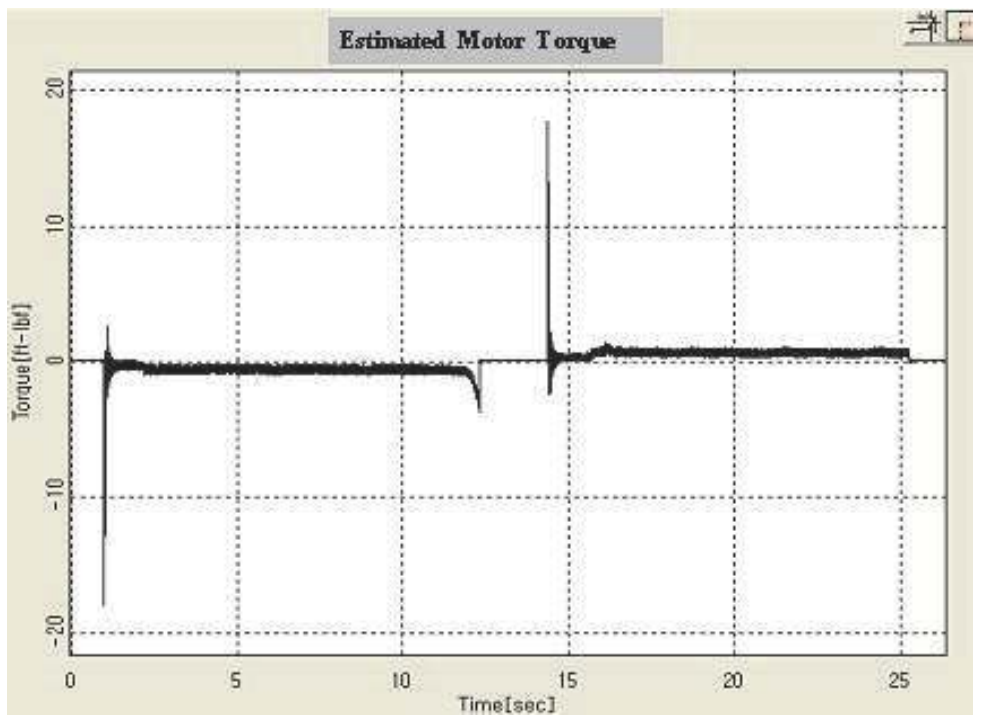

Fig. 3. An example of motor torque signal estimated by NEET 


\subsubsection{Efficiency calculation}

By substituting the estimated motor torque, the measured actuator torque, and the overall gear ratio provided by manufacturer into the equation (1) the efficiency can be calculated easily.

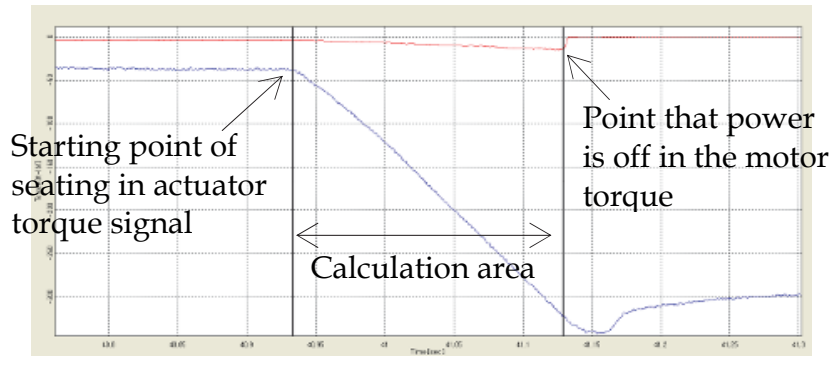

Fig. 4. An example of efficiency calculation area

In this study, the added algorithm into the NEET for the calculation of efficiency was used, and the efficiency calculation procedures from the algorithm are as follows:

a. Read the estimated motor torque signal.

b. Read the measured actuator torque signal.

c. Input the overall gear ratio.

d. Establish the area to be analyzed from the two signals above (Fig. 4): the left and right reference points of the area were set up based on the starting point of seating in the actuator torque signal, and the point in the motor torque signal where power is turned off, respectively.

e. Calculate the actuator efficiency of each point within the established area, including the reference points by using the equation (1) (Fig. 5).

f. Calculate the average actuator efficiency by dividing the total sum of efficiency of each point by the total number of points in the area. As a matter of convenience, the average actuator efficiency is referred to as the actuator efficiency henceforth.

g. Calculate the two 'as-left' actuator efficiencies of the design basis test, and 'as-found' efficiency of the periodic test for each valve by applying the procedures from (a) to (f).

h. Calculate the average value of the two 'as-left' actuator efficiency (avg. 'as-left' efficiency), the difference between avg. 'as-left' efficiency and the 'as-found' efficiency ( $\triangle$ efficiency), and the time interval between design basis test and periodic test needed to analyze the efficiency behavior over time.

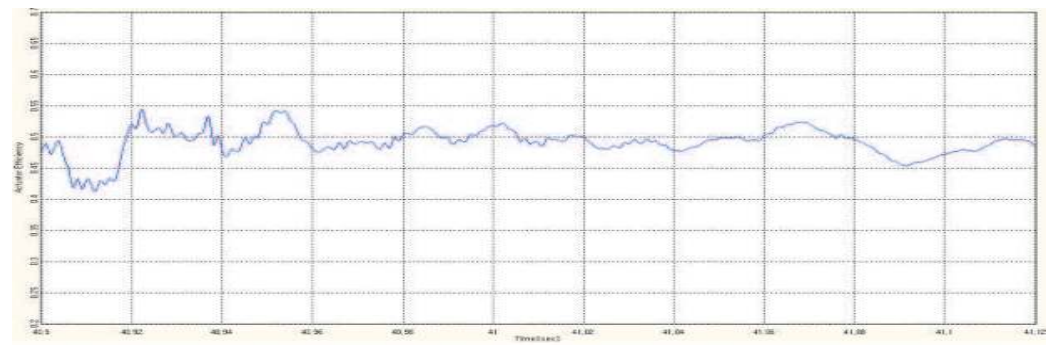

Fig. 5. An example of calculated actuator efficiency for each point 


\subsection{Efficiency behavior analysis process}

As the known equation (1), actuator efficiency is dependent on motor torque, actuator torque, and the overall gear ratio. One of the important parameters in determining the motor torque output is motor speed. In addition, one of the important parameters in determining the actuator torque output is maximum motor torque rating. Accordingly, the motor speed, maximum motor torque rating, and overall gear ratio were selected as major factors in analyzing the efficiency behavior for gate and globe valves. The design information about these factors included in this study is described in Table 1.

The efficiency behavior by the three factors described above was analyzed according to the following process:

a. Analyze the distribution of the avg. 'as-left' and 'as-found' efficiencies based on the testto-test time interval in order to address the potential degradations with the passage of time. The time interval covers the efficiency variations over a period of several years.

b. Compare the avg. 'as-left' and 'as-found' efficiency with the design efficiency. In this study, the pullout efficiency, which is the lowest efficiency among the staring, stall and pullout efficiencies usually provided by manufacturers, was selected as the design efficiency because most nuclear power plants use the efficiency in the calculation of the actuator output torque.

c. Modify the design efficiency based on the analysis results of item (b), if necessary.

\begin{tabular}{lcccccc}
\hline $\begin{array}{l}\text { Motor } \\
\text { Manufacturer }\end{array}$ & $\begin{array}{l}\text { Motor } \\
\text { Speed } \\
(\text { RPM) }\end{array}$ & $\begin{array}{l}\text { Actuator } \\
\text { Manufacturer }\end{array}$ & $\begin{array}{l}\text { Actuator } \\
\text { Model }\end{array}$ & $\begin{array}{l}\text { Overall } \\
\text { Gear Ratio }\end{array}$ & $\begin{array}{l}\text { Max. } \\
\text { Torque } \\
\text { Rating }\end{array}$ & $\begin{array}{l}\text { Design } \\
\text { Efficiency }\end{array}$ \\
\hline Reliance & 1800 & Limitorque & SMB-000 & $33.5 \sim 62.5$ & 120 & 0.4 \\
& & & SMB-00 & $23 \sim 81.1$ & 260 & 0.4 \\
& & SMB-0 & $34.9 \sim 54.8$ & 700 & 0.4 \\
& & SMB-1 & $50.4 \sim 60.1$ & 1100 & 0.4 \\
& & SMB-2 & $26.4 \sim 67.4$ & 1950 & 0.35 \\
& & & $53.7 \sim 70.9$ & 4200 & 0.4 \\
& & SMB-3 & 98.6 & & 0.38 \\
& & & AMB-000 & 36.5 & 120 & 0.4 \\
& & SMB-00 & $34.1 \sim 41$ & 260 & 0.45 \\
& & & 67.5 & & 0.4 \\
& & SMB-0 & $31.3 \sim 39.1$ & 700 & 0.45 \\
& & SMB-1 & $27.2 \sim 35.9$ & 1100 & 0.45 \\
& & SMB-2 & $46.6 \sim 82.5$ & 1950 & 0.4 \\
& & SMB-3 & $66.1 \sim 70.9$ & 4200 & 0.4 \\
& & & &
\end{tabular}

Table 1. Design information of tested valves 


\section{Efficiency behavior}

Fig. 6 to 8 depict the actuator efficiency distribution for the avg. 'as-left' efficiency ( $\diamond$ blue), 'as-found' efficiency ( $\square$ red), and $\triangle$ efficiency ( $\triangle$ green) by motor speed, maximum motor torque rating, and overall gear ratio, respectively. In the figures, the $x$-axis is the time interval between the design basis test and the periodic test. The y-axis includes the actuator efficiency and $\triangle$ efficiency $(-0.2$ to +0.2$)$. The figures also include the design efficiency provided by manufacturer. Based on the results displayed in the figures, the efficiency behaviors over time were analyzed.

\subsection{Motor speed}

The efficiency distribution of the actuators with design efficiency, 0.4 was shown in Fig. 6 by the motor speed 1800 RPM (Fig. 6a) and 3600 RPM (Fig. 6b). In both figures, $\triangle$ efficiency was distributed in the positive and negative areas evenly over time. The actuator efficiencies have variations in efficiency from test-to-test, but no increasing or decreasing trend over time. However, from the distribution of the avg. 'as-left' efficiency and 'as-found' efficiency, most of the actuators with 3600 RPM are observed to possess greater efficiency than the design efficiency, 0.4, while some actuators with 1800 RPM have lower efficiency than the design efficiency. From those observations, we concluded that motor speed does not affect the age-related or service-related degradation, while the efficiency of actuators with 1800 RPM can be susceptible to a decrease below the design efficiency.

\subsection{Overall gear ratio}

In order to analyze if the OVR affects the potential degradation in efficiency, the various OVRs were grouped by 20 40, 40 60, and 60 80 (Fig. 7a, 7b, 7c). The design efficiency of the groups is 0.4 . In the three figures, $\triangle$ efficiency was distributed in the positive and negative areas evenly over time. The actuator efficiencies have variations in efficiency from test-totest, but no increasing or decreasing trend over time.

However, the greater number of actuators was distributed in the area below design efficiency as the OVR increased. From those observations, we concluded that OVR does not affect the age-related or service-related degradation, while the efficiency of actuators with more OVR can be susceptible to a decrease below the design efficiency.

\subsection{Maximum motor torque rating}

The efficiency distribution of the various actuators was shown in Fig. 8 by the maximum motor torque rating (Fig. 8a to Fig. 8n). In the figures, $\triangle$ efficiency was distributed in the positive and negative areas evenly over time. The actuator efficiencies have variations in efficiency from test-to-test, but no increasing or decreasing trend over time.

Some valve's efficiencies of 120 and 260 of maximum motor torque rating with an 1800 RPM motor (Fig. 8a, 8b) were showing up in the region below the design efficiency line. However, such trends appeared in the other actuators only with the 1800 RPM motor. The design efficiencies for those actuators were considered still available because data points showing such behavior are less than two at most for an actuator, and the deterioration from the design efficiency is small and can be explained based on the following engineering judgments. First, one avg. 'as-left' efficiency of 700 of maximum motor torque rating is lower than the design efficiency (Fig. 8c) but the behavior was considered temporary because the 
'as-found' efficiency was recovered up to the design efficiency. The same behavior was also observed for 1950 of maximum motor torque rating (Fig. 8e). In the Fig. 8e, both avg. 'as-left' and 'as-found' efficiency were lower than the design efficiency, but the maximum deviation from the design efficiency was less than $11 \%$ approximately, which is an approximation of the sum of $8 \%$ for uncertainty of sensors for stem torque and $3 \%$ uncertainty of motor torque estimator based on NEET.

From these observations, maximum motor torque rating does not affect the efficiency degradation over time, but lower motor torque rating could have lower efficiency than the design only, for 120 and 260 of maximum motor torque rating with the 1800 RPM motor.

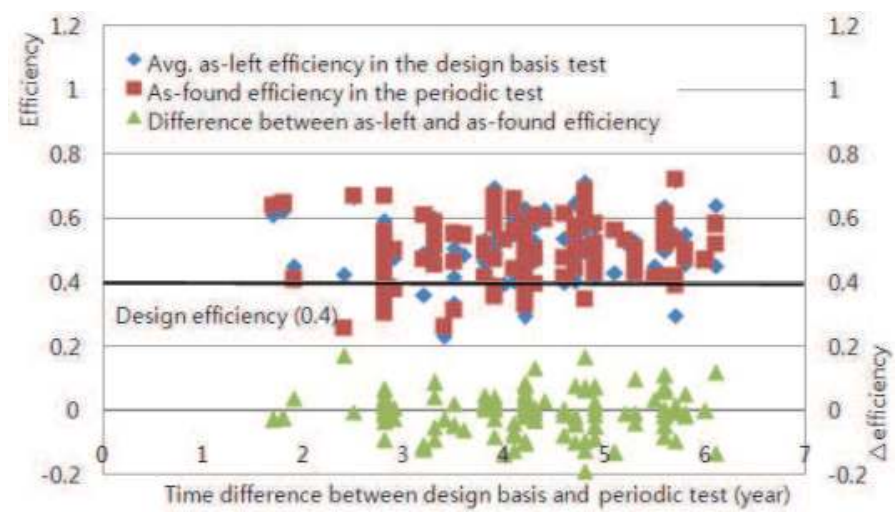

(a) 1800 RPM

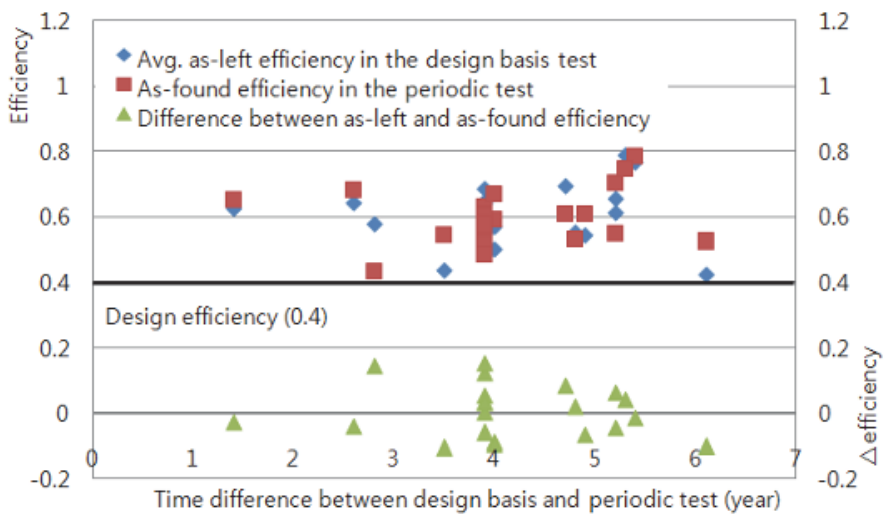

(b) 3600 RPM

Fig. 6. Efficiency distribution by motor speed 


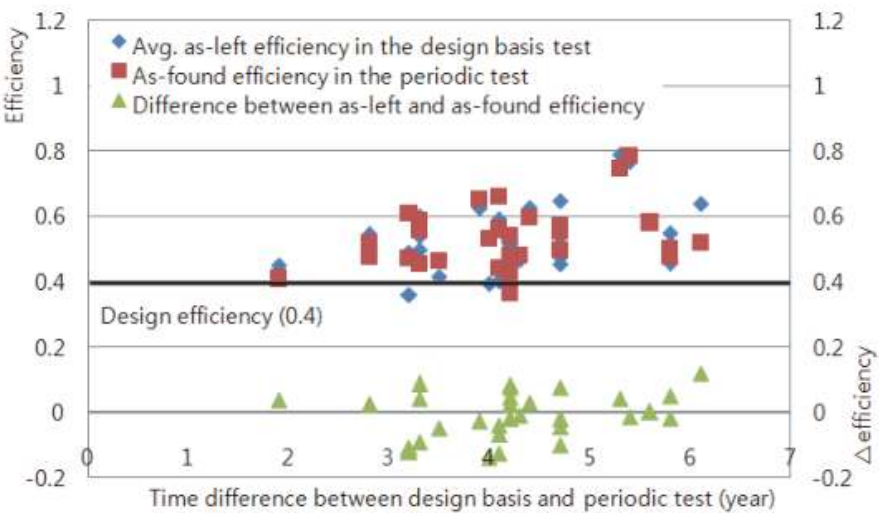

(a) OVR 20 40

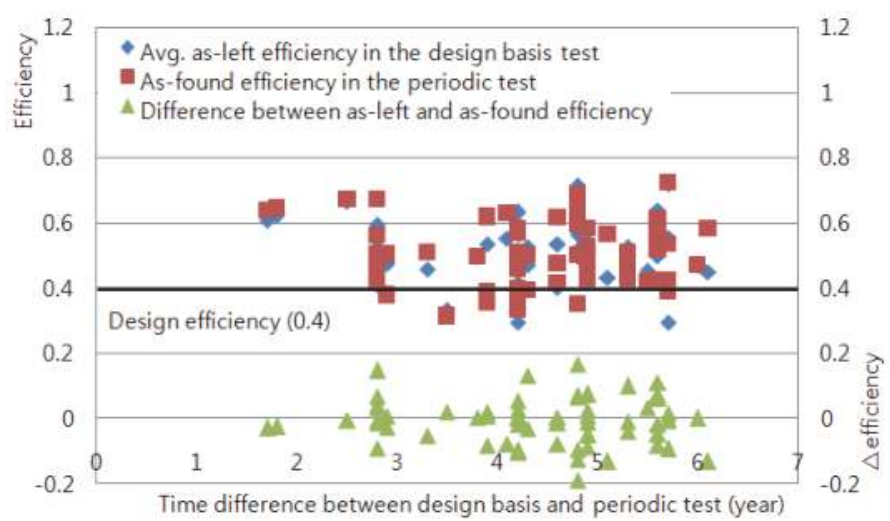

(b) OVR 40 60

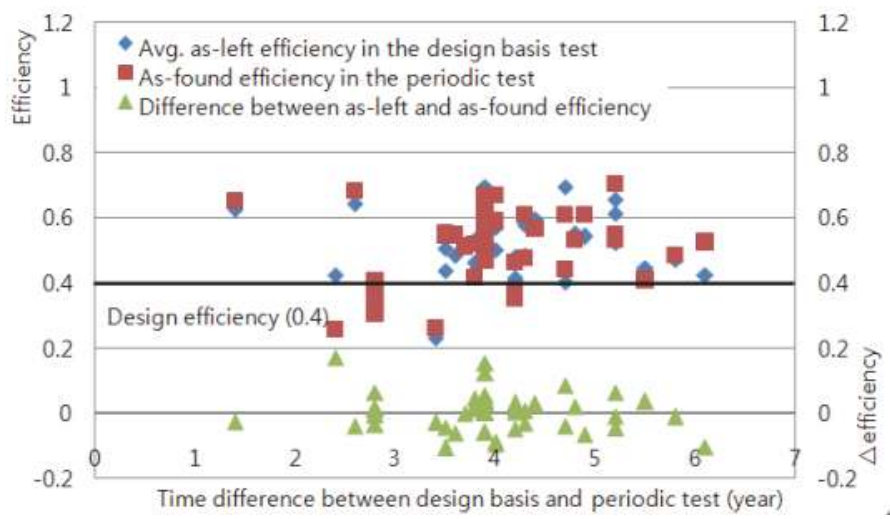

(c) OVR 60 80

Fig. 7. Efficiency distribution by OVR 

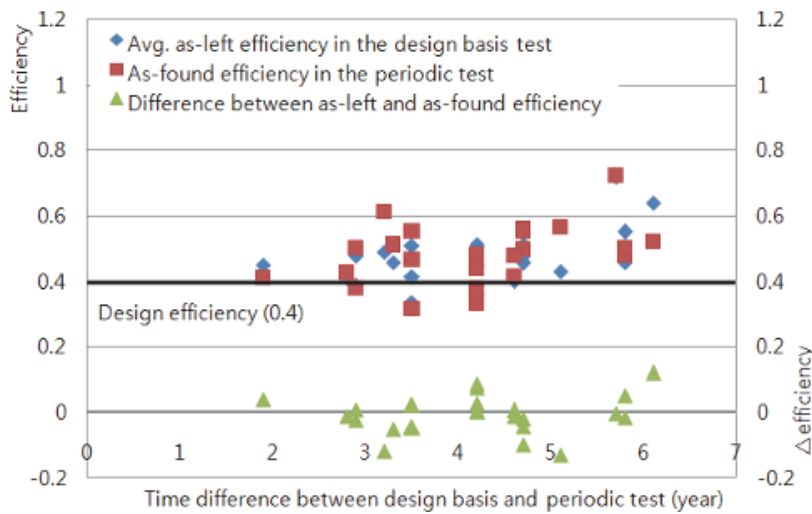

(a) 120 of max. motor torque rating (1800 RPM)
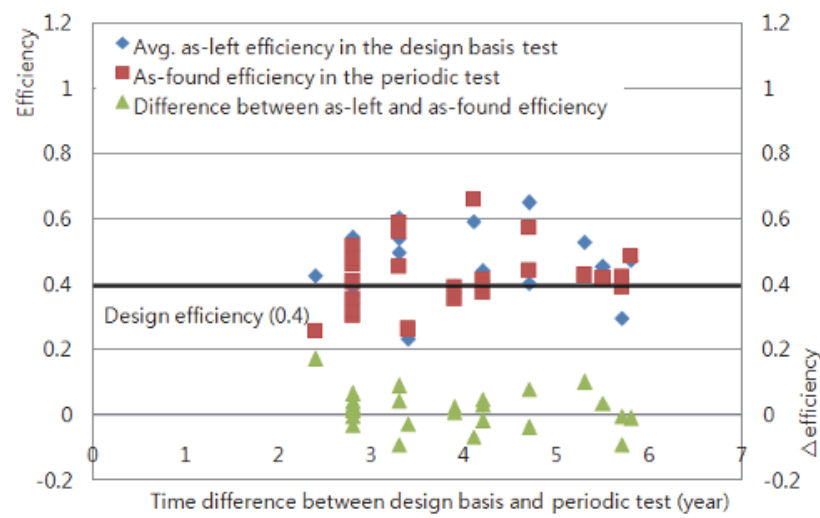

(b) 260 of max. motor torque rating (1800 RPM)

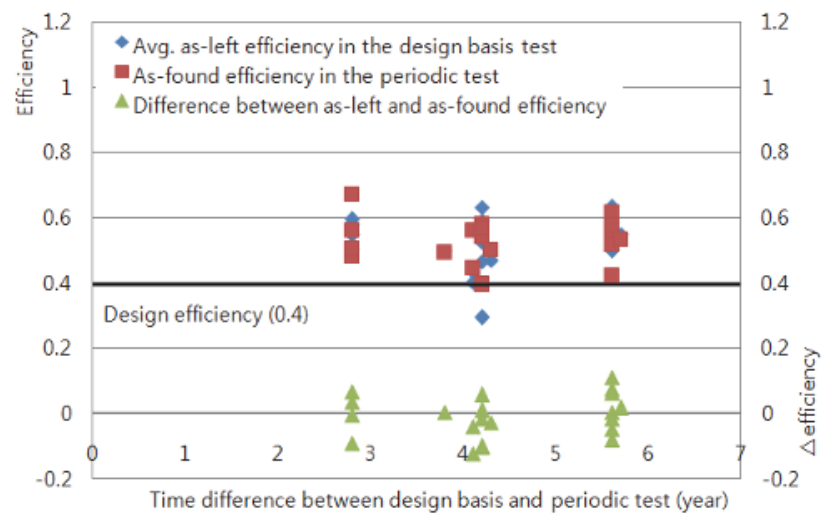

(c) 700 of max. motor torque rating (1800 RPM) 


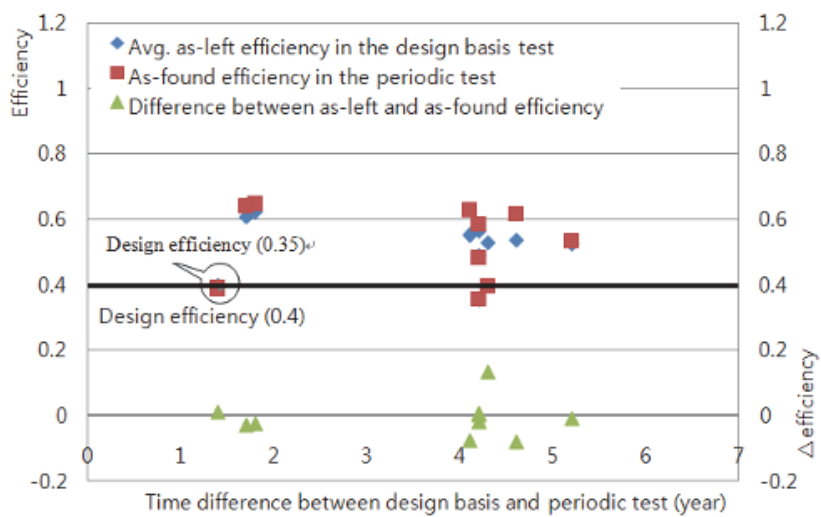

(d) 1100 of max. motor torque rating (1800 RPM)

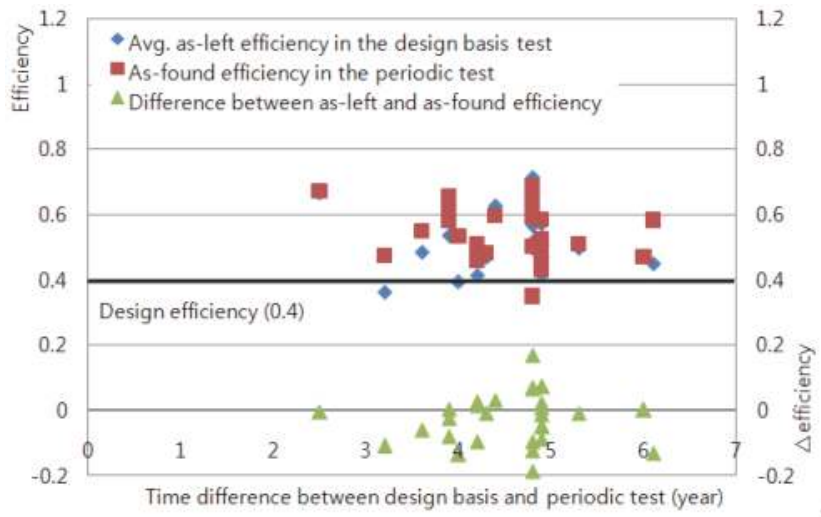

(e) 1950 of max. motor torque rating (1800 RPM)

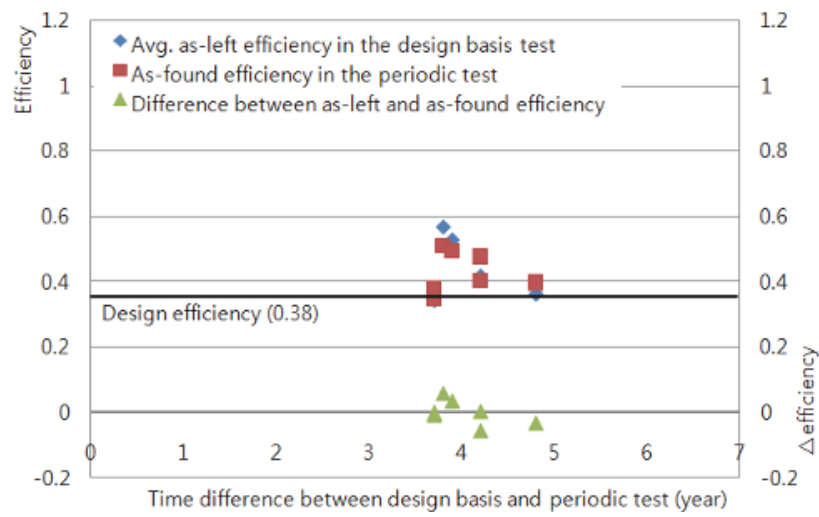

(f) 4200 of max. motor torque rating (1800 RPM, 53.7 70.9 OVR) 


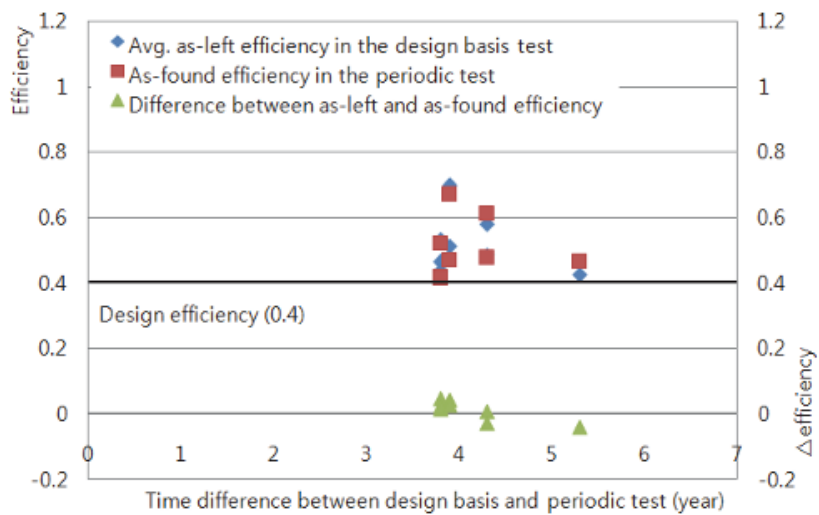

(g) 4200 of max. motor torque rating (1800 RPM, 98.6 OVR)

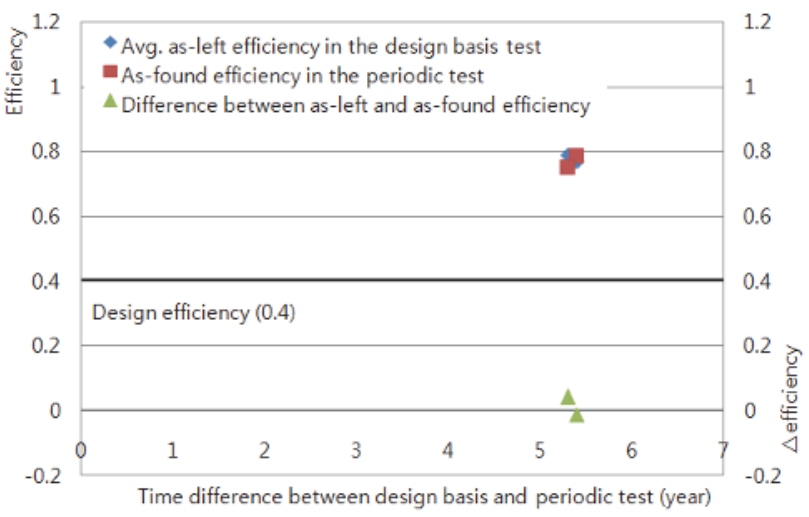

(h) 120 of max. motor torque rating (3600 RPM)

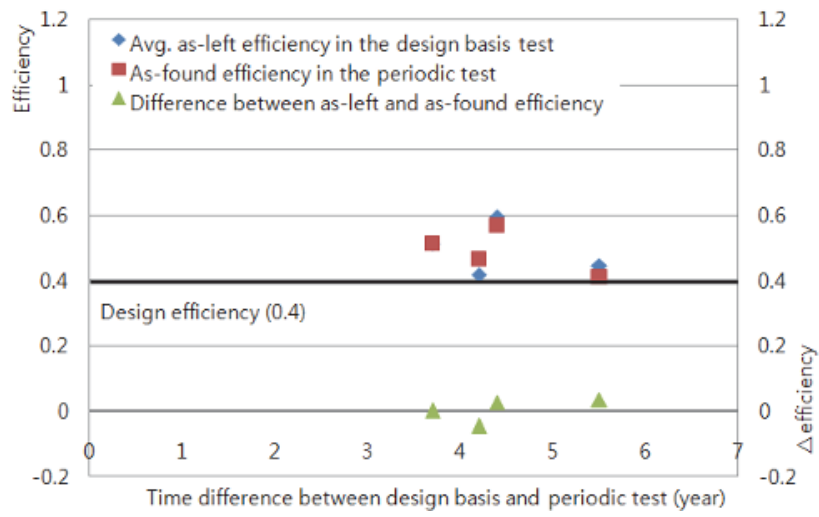

(i) 260 of max. motor torque rating (3600 RPM, 34.1 41 OVR) 


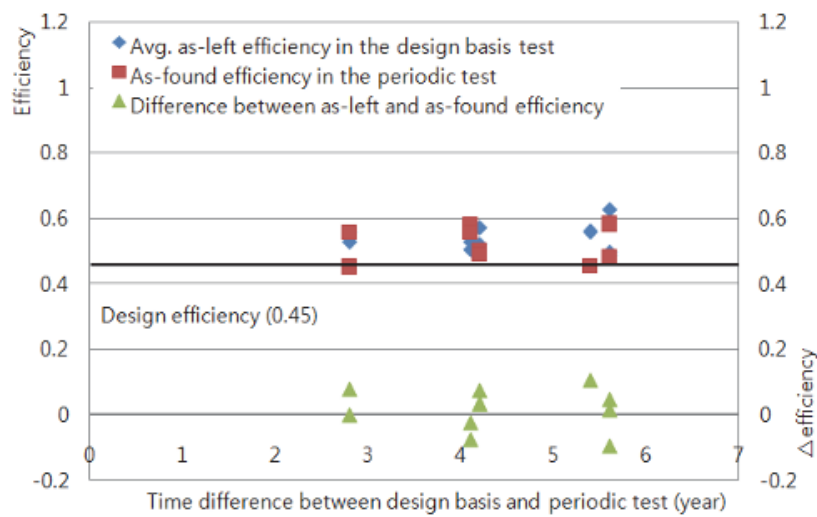

(j) 260 of max. motor torque rating (3600 RPM, 67.5 OVR)

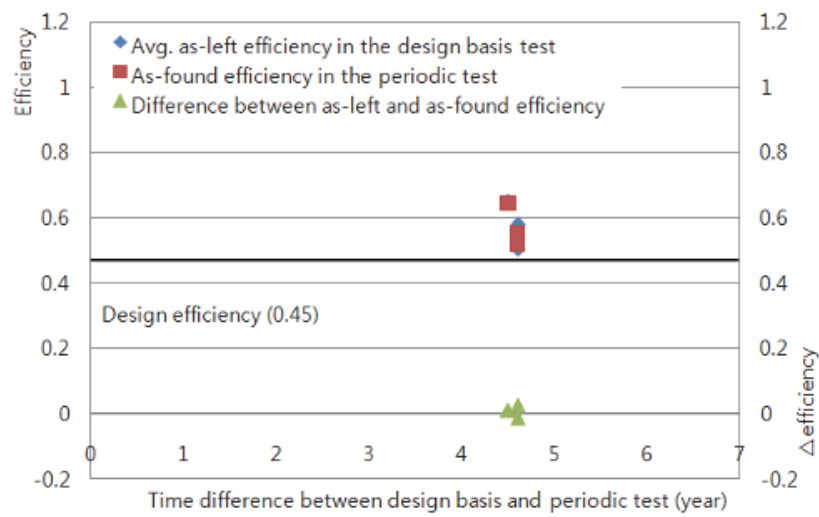

(k) 700 of max. motor torque rating (3600 RPM)

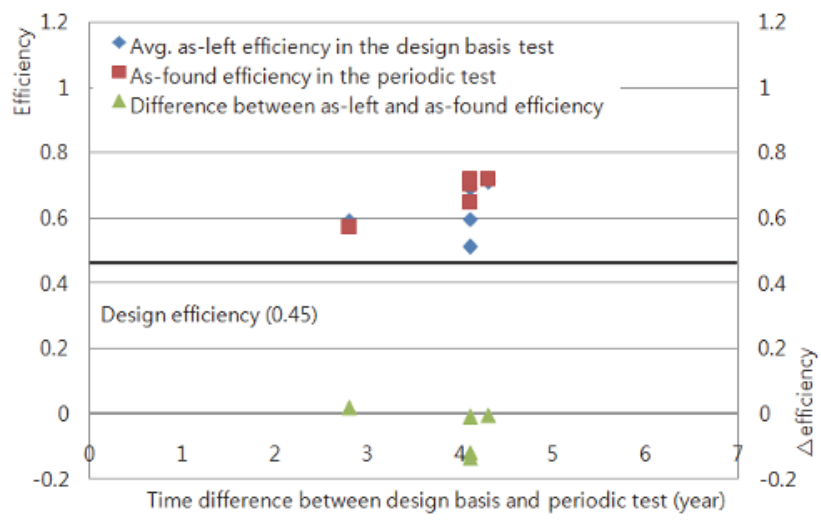

(1) 1100 of max. motor torque rating (3600 RPM) 


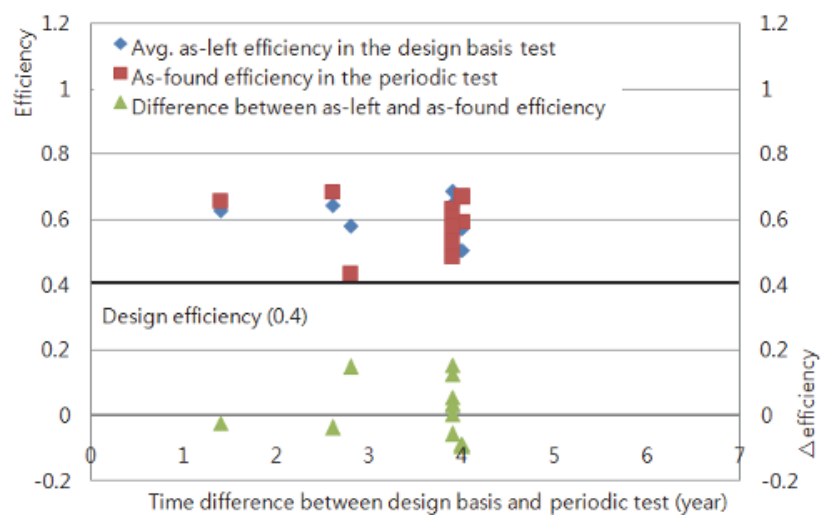

(m) 1950 of max. motor torque rating (3600 RPM)

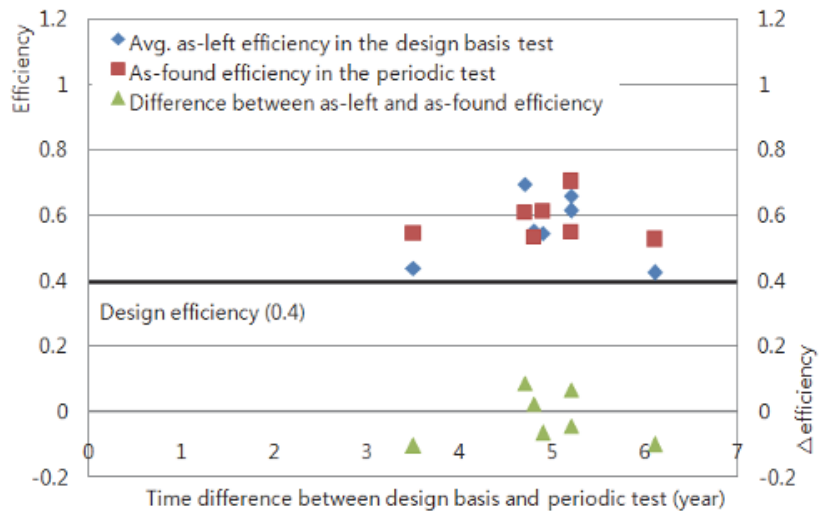

(n) 4200 of max. motor torque rating (3600 RPM)

Fig. 8. Efficiency distribution by max. motor torque rating

\section{Threshold value calculation}

As described in Section 3, the actuator efficiency of gate and globe valves have variations in efficiency from test-to-test, but no increasing or decreasing trend over time. Some of the variation is due to, for example, uncertainty in test measurements or in the estimation of motor torque. Some of the variation can be due to random variation in efficiency. Although the efficiencies of the two actuators, 120 and 260 of motor torque rating with an 1800 RPM motor, also were not increased or decreased over time, where their values are susceptible to be lower than design values. The decrease can be due to the various combinations of causes such as lower motor speed, lower maximum motor torque rating, overall gear ratio, operational environment, maintenance history after installation of those valves. For those actuators, change of design efficiency is needed to verify proper MOV setup and to quantify operational margin, as well as to provide any needed information on potential actuator degradation. Therefore, the threshold efficiencies for the two actuators are established using a deterministic approach (JOG, 1994), based on engineering judgment, which bounds $95 \%$ of 
the efficiency data. This is shown by the dashed lines in Fig. 9 and Fig. 10 of the labeled threshold boundary. The intersection of a $+45^{\circ}$ line and a horizontal line at $\triangle$ efficiency $=0$ creates a wedge-shaped boundary. For points on the $+45^{\circ}$ line, design efficiency $+\triangle$ efficiency $=0$ constant. In other words, all data points on such a line will end up at the same final efficiency after a change in efficiency occurs. Points to the right of the line will end up at a higher efficiency and points to the left of the line will end up at a lower efficiency. The $\triangle$ efficiency $=0$ line is also used as a discriminator because points with negative $\triangle$ efficiency (below the line) are not a concern regarding potential decrease in efficiency. This threshold boundary can be positioned until a place is found where $5 \%$ of the data lie to the left of the +45 line and above the $\triangle$ efficiency $=0$ line (i.e., within the $135^{\circ}$ wedge). In this position, the intercept of the $+45^{\circ}$ line with the $x$-axis is the threshold efficiency. For $95 \%$ of the data, efficiency decreases will not result in a final efficiency exceeding the threshold. Using this approach, a threshold value that bounds 95\% (1 out of the 25 data points in Fig. 9 and 1 out of the 26 data points in Fig. 10) of the data for maximum torque rating 120 and 260 with 1800 $\mathrm{RPM}$ motor is determined as 0.332 and 0335 , respectively.

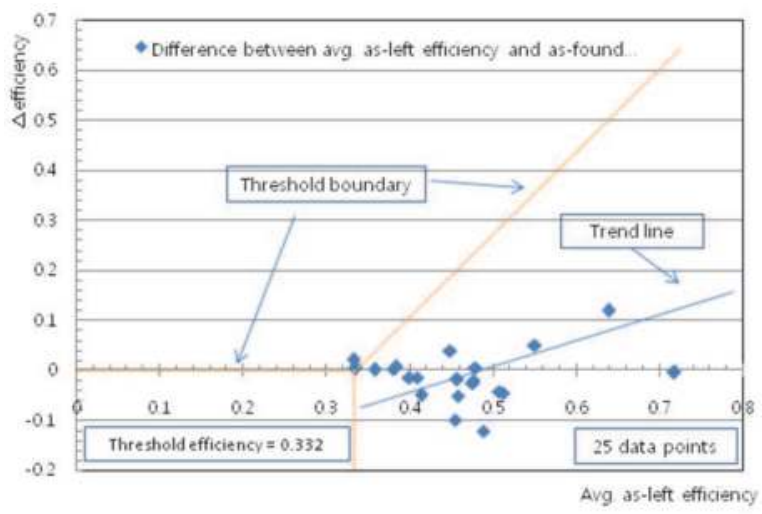

Fig. 9. Threshold efficiency for motor torque rating, 120 with 1800 RPM

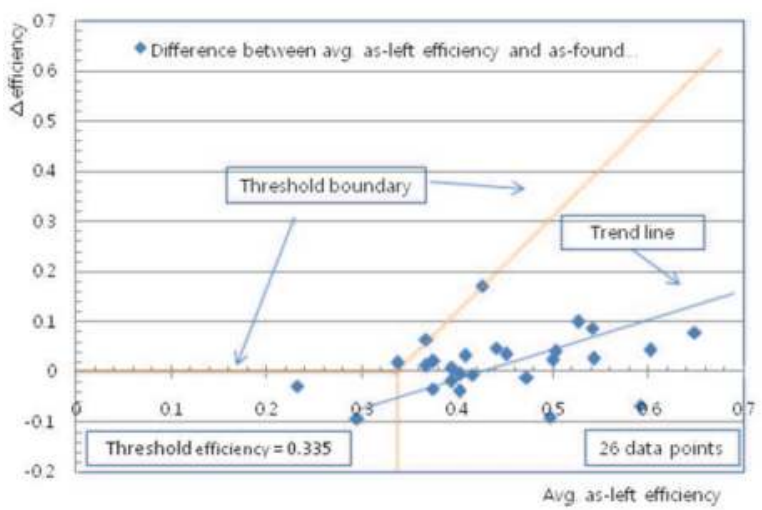

Fig. 10. Threshold efficiency for motor torque rating, 260 with 1800 RPM 


\section{Conclusion}

The actuator efficiency has variations in efficiency from test-to-test, but no increasing or decreasing trend over time. In other words, there is no potential degradation in efficiency due only to the passage of time. Under certain conditions, however, decreases in efficiency to below the design efficiency were observed. Specifically, the actuators with low speed, low actuator size, and high gear ratio are susceptible to decrease in efficiency. However, these decreases tend to occur progressively down to a plateau level because those actuators have variations in efficiency from test-to-test, but no increasing or decreasing trend over time.

In this chapter, the two actuators that have 120 and 160 of motor torque rating with an 1800 RPM motor appeared to possess those behaviors. For the two actuators, change of design efficiency is needed to verify proper MOV setup and to quantify operational margin, as well as to provide any needed information on potential actuator degradation. Accordingly, the threshold efficiencies for the 120 and 160 of motor torque rating which bounds $95 \%$ of the efficiency data were determined as 0.332 and 0.335 , respectively. The threshold values and efficiency behaviors over time can be applied only for the actuators described in the Table 1 , because the design efficiencies and features of actuators depend on manufacturers. However, when it is assumed that design efficiencies are pertinent for some actuators, it can be possible to evaluate the potential degradation in design efficiencies only for the actuators with lower speed motor, lower actuator size, and higher gear ratios based on the results of this chapter.

\section{Acknowledgment}

The authors express their sincere appreciation to KHNP (Korea Hydro \& Nuclear Power Company) for its support in the behavior analysis of the actuator efficiency.

\section{References}

USNRC, Generic Letter 89-10 (1989). Safety Related Motor Operated Valve Testing and Surveillance, USA

USNRC, Generic Letter 96-05 (1996). Periodic Verification of Design-Basis Capability of Safety-Related Motor-Operated Valves, USA

S.C. Kang, S.K. Park, D.H. Lee, Y.S. Kim (2006). Motor Control Center (MCC) Based Technology Study for Safety-Related Motor Operated Valves, Nuclear Engineering and Technology, Vol. 38, No. 2, 155-162.

JOG, (2004). Joint Owners' Group (JOG) Motor Operated Valve Periodic Verification Program Summary, pp. E1-E2, USA. 


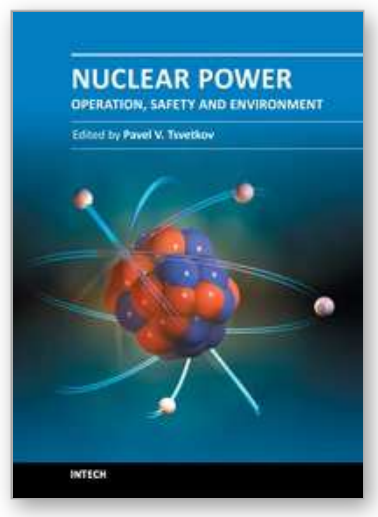

\author{
Nuclear Power - Operation, Safety and Environment \\ Edited by Dr. Pavel Tsvetkov
}

ISBN 978-953-307-507-5

Hard cover, 368 pages

Publisher InTech

Published online 06, September, 2011

Published in print edition September, 2011

Todayâ $€^{\mathrm{TM}} \mathrm{S}$ nuclear reactors are safe and highly efficient energy systems that offer electricity and a multitude of co-generation energy products ranging from potable water to heat for industrial applications. At the same time, catastrophic earthquake and tsunami events in Japan resulted in the nuclear accident that forced us to rethink our approach to nuclear safety, design requirements and facilitated growing interests in advanced nuclear energy systems, next generation nuclear reactors, which are inherently capable to withstand natural disasters and avoid catastrophic consequences without any environmental impact. This book is one in a series of books on nuclear power published by InTech. Under the single-volume cover, we put together such topics as operation, safety, environment and radiation effects. The book is not offering a comprehensive coverage of the material in each area. Instead, selected themes are highlighted by authors of individual chapters representing contemporary interests worldwide. With all diversity of topics in 16 chapters, the integrated system analysis approach of nuclear power operation, safety and environment is the common thread. The goal of the book is to bring nuclear power to our readers as one of the promising energy sources that has a unique potential to meet energy demands with minimized environmental impact, near-zero carbon footprint, and competitive economics via robust potential applications. The book targets everyone as its potential readership groups - students, researchers and practitioners - who are interested to learn about nuclear power.

\title{
How to reference
}

In order to correctly reference this scholarly work, feel free to copy and paste the following:

Shin Cheul Kang, SungKeun Park, DoHwan Lee, YangSeok Kim and DaeWoong Kim (2011). A Study on the Actuator Efficiency Behavior of Safety-Related Motor Operated Gate and Globe Valves, Nuclear Power Operation, Safety and Environment, Dr. Pavel Tsvetkov (Ed.), ISBN: 978-953-307-507-5, InTech, Available from: http://www.intechopen.com/books/nuclear-power-operation-safety-and-environment/a-study-on-theactuator-efficiency-behavior-of-safety-related-motor-operated-gate-and-globe-valves

\section{INTECH}

open science | open minds

\section{InTech Europe}

University Campus STeP Ri

Slavka Krautzeka 83/A

51000 Rijeka, Croatia

Phone: +385 (51) 770447

\section{InTech China}

Unit 405, Office Block, Hotel Equatorial Shanghai

No.65, Yan An Road (West), Shanghai, 200040, China 中国上海市延安西路65号上海国际贵都大饭店办公楼 405 单元 Phone: +86-21-62489820 
Fax: +385 (51) 686166

Fax: +86-21-62489821

www.intechopen.com 
(C) 2011 The Author(s). Licensee IntechOpen. This chapter is distributed under the terms of the Creative Commons Attribution-NonCommercialShareAlike-3.0 License, which permits use, distribution and reproduction for non-commercial purposes, provided the original is properly cited and derivative works building on this content are distributed under the same license. 